Uzunay, A.Ş., Kalfaoğlu, S. ve Akgemci, T. (2020). Sosyal Jet-Lag Sendromu Üzerine Bir Değerlendirme. Sosyal Araştırmalar ve Yönetim Dergisi, (1), 53-61.

\title{
SOSYAL JET-LAG SENDROMU ÜZERİNE BİR DEĞERLENDİRME
}

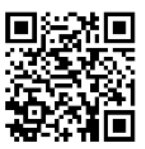

https://doi.org/10.35375/sayod.735128 Aybanu Șüheda UZUNAY', Serap KALFAOĞLU² ${ }^{2}$ Tahir AKGEMCI ${ }^{3}$

\section{ÖZET}

Sosyal jet-lag sendromu, hafta sonları uyku düzeni değiştirildiğinde, geç yatıp geç kalkıldığında, dolayısıyla vücudun doğal uyku düzeninin bozulduğunda ortaya çıkmaktadır (Roenneberg, 2012). Bu sendroma yakalanan çalışan insanın obezite gibi olumsuz biyolojik sonuçlarla karşılaşma ihtimali artarken; uyku hali, yorgunluk, kötü ruh hali, depresyon gibi olumsuz sosyo-psikolojik etkilere de maruz kaldığı görülmektedir.

Bu çalışma, sosyal jet-lag üzerine farkındalığı artırmak ve yüz yüze katılım ile özellikle bu sendroma maruz kalmış insanların yaşadığı sosyo-psikolojik etkileri ortaya çıkarmak amacını taşımaktadır. Bu amaçla, Konya ilinde bir işletme çalışanları üzerine bir araştırma yapılmıştır. Araştırma, nitel araştırma yöntemini esas alan, olgu bilim deseni kullanılarak hazırlanmıştır. Araştırmada kullanılan teknik ise yarıyapılandırılmış görüşme tekniğidir. Görüşmeler sonucunda, çalışanların sendroma ilişkin farkındalık düzeyi, çalışma yaşamlarına yansıyan etkileri ve sendromla başa çıkmada kullandıkları yöntemler açıklanmış; kişinin kendisine uygun bir uyku ritmine sahip olmasıyla çalışma yaşamındaki etkileri üzerine değerlendirmeler yapılmıştır.

Anahtar Kelimeler: Sosyal Jet-Lag Sendromu, Uyku, Biyolojik Saat, Sirkadiyen.

\section{AN EVALUATION ON SOCIAL JET-LAG SYNDROME}

\section{SUMMARY}

Social jet-lag syndrome occurs when the sleep pattern is changed on the weekends, when you go to bed late and get up late, so when the body's natural sleep pattern is disturbed (Roenneberg, 2012). While the probability of working people suffering from this syndrome to experience negative biological consequences such as obesity increases; it is observed that they are also exposed to negative sociopsychological effects such as somnolence, fatigue, bad mood and depression.

This study aims to raise awareness on social jet-lag and to reveal the socio-psychological effects experienced by people who have been exposed to this syndrome through face-to-face participation. For this purpose, a research has been conducted on a business employees in Konya. The research has been prepared by using a case study pattern based on qualitative research method. The technique used in the research is semi-structured interview technique. As a result of the interviews, the awareness level of the employees about the syndrome, the effects reflected on their working lives and the methods they used to

\footnotetext{
${ }^{1}$ YL Öğr., Selçuk Üniversitesi, SBE, Yönetim ve Organizasyon ABD, aybanuzunay@ gmail.com ORCID ID: https://orcid.org/0000-0002-0044-722X

${ }^{2}$ Arş. Gör., Selçuk Üniversitesi, İ̈BF, İşletme Bölümü, serapkalfaoglu@ selcuk.edu.tr, ORCID ID: https://orcid.org/ 0000-0002-7248-8370

${ }^{3}$ Prof., Dr., Selçuk Üniversitesi, İ̈B, İşletme Bölümü, takgemci@ selcuk.edu.tr, ORCID ID: https://orcid.org/ 00000001-5936-7462
} 
deal with the syndrome have been explained; evaluations have been made on the effects of the person on working life by having a suitable sleep rhythm.

Keywords: Social Jet-Lag Syndrome, Sleep, Biological Clock, Circadian

\section{GíRiș}

Herkesçe bilinmektedir ki, modern iş yaşamı hızlı ve popüler olmayı gerektirmiş ve rakiplere karşı çoğu zaman acımasız olunması zorunluluğunu doğurmuştur. İçinde bulunulan çağın bu özellikleri dikkate alındığında, insan daha fazla çalışmakta, daha az uyumakta ve farklı boyutlardaki ekranlara bakarak sağlıksız zaman harcamaktadır. Söz konusu yeni gerçeklik, kaçınılmaz olarak yeni sağlık risklerini de beraberinde getirmektedir (Clark, 2019).

Son y1llarda uyku konusunda uzmanlar, "sosyal jet-lag" adı verilen uyku bozukluğunun insan sağlı̆̆1 üzerindeki uzun dönemli olumsuz sonuçlarına dikkat çekmiştir. Sosyal jet-lag, hafta sonları uyku düzeni değiştirildiğinde, geç yatıp geç kalkıldığında, dolayısıyla vücudun doğal uyku düzeninin bozulduğunda ortaya çıkmaktadır. Kavramın tanımı ilk olarak, Münih'teki Ludwig-Maximilian Üniversitesi'nde Kronobiyoloji Profesörü olan Till Roenneberg tarafindan 2012 yılında "Internal Time (Vücut Saati)" adl1 kitapta yapılmıştır (Burda, 2017).

Normal jet-lag yaşayan herkes tarafından bilindiği üzere, jet-lag'ın en belirgin semptomlarından biri uyku problemidir. Vücudun yeni bir zaman dilimine uyum sağlaması biraz zaman alır - ki bu süre genellikle geçtiğiniz her zaman dilimi için bir günü temsil eder-. Benzer şekilde, Roenneberg de konu üzerine; "Sosyal jet-lag ve uyku yoksunluğu neredeyse birbirinden ayrılamaz." demiştir (Geddes, 2019).

Sosyal jet lag sendromu nispeten yeni bir terim olmasına karşı1ık, İngiltere gibi sanayileşmiş ülkelerdeki insanların yaklaşı1k \%87'si bu rahatsızlıktan muzdariptir. Sendromun etkileri gerçek bir jet-lag sendromunu yansitır ve günlük görevlerden uzun dönemli sağlığı içine alan her şeyi etkileyebilir. Ayrıca sendrom, yeterli güneş ışığının alınmamasının doğrudan bir sonucu olarak da ortaya çıkmaktadır. Vücudun doğal biyolojik döngüsü ile sosyal norm olduğuna inanmak için şartlandırılan şey arasındaki tutarsızlıktır (Malbon, 2018).

Konu üzerine farkındalığı artırmak ve yüz yüze katılım ile özellikle bu sendroma maruz kalmış insanların yaşadığı sosyo-psikolojik etkileri ortaya çıkarmak amacıyla hazırlanan bu çalışmada, ilerleyen kısımlarda, sendromun konunun uzmanları tarafindan açıklamalarına ve detaylıca nedenlerine yer verilmiştir. Ayrıca bu sendromla başa çıkma yollarından birkaç tanesi sunularak, yol gösterici olmak hedeflenmiştir. Sendroma ilişkin oluşturulan kuramsal çerçeve sonrası bir kooperatifte çalışan kişilere Ekteki sorular sorularak sendromun etkileri bizzat gözlenmiş ve yorumlanmıştır.

\section{SOSYAL JET-LAG SENDROMU ÜZERINE KAVRAMSAL ÇERÇEVE}

Sosyal jet-lag, iki farklı uyku düzenine sahip olma alıskanlığını tanımlar. Genellikle bu farklılık hafta içi ve hafta sonu rutini arasında ortaya çıkar. İnsan vücudunda ne zaman uyuması gerektiğini kendisine hatırlatan sirkadiyen ritim adı verilen akıllı bir yerleşik sistem vardır. Birçok insanın biyolojik süreci ve davranışsal fonksiyonu, metabolizması, hormon salgıs1 ve vücut 1sısından uyku-uyanıklık kalıplarına ve sosyalleşmeye kadar değişen endojen yapısı, sirkadiyen saatler tarafindan yönlendirilen 24 saatlik ritimler sergiler. İnsanlar arasındaki bu endojen günlük varyasyonlar, sirkadiyen saatler tarafından kontrol edilen, ancak dış çevresel faktörlerden etkilenebilen "kronotip" ile belirlenebilir. Sirkadiyen ritim hassastır ve onunla senkronize olmayan bir yaşam tarzı geliştirildiğinde, uyku sağlığında bozukluklar ortaya çıkar. Birçoğu için, bu 'çifte yaşam' jet gecikmesine çok benzeyen fiziksel semptomlarla sonuçlanır. Bununla birlikte, sosyal jetlag, bir zaman diliminden diğerine basit bir geçişten daha karmaş̧ıtır. Sosyal ve 'normal' jet gecikmesi arasındaki ana farklardan biri ise 1şıktan etkilenme düzeyidir. Oldukça akıllı olan sirkadiyen ritim bunu tanır ve kendisini sıfirlar. Sosyal jet-lag, rutin bir değişim içerir, ancak fiziksel 
konum değişikliği olmadığ için farklılıklar taşısa da sonuç, travma ve uyku düzeni bozukluğudur (Clark, 2019; Wittmann vd., 2006: 498-501). Araştırmacı Sierra Forbush da, insan vücudundaki hemen hemen tüm hormonların bir çeşit sirkadiyen ritim üzerinde olduğu vurgusunu yaparak, uyku zamanının değiştirildiğinde, tüm sistemin olması gerektiği kadar verimli çalışmadığını dile getirmiştir. Yakın zamanda, 984 yetişkin üzerinde yaptığı bir çalışmadan, bir kişinin her hafta yaşadığı sosyal jet-lag için kardiyovasküler hastalık olma ihtimalinde \%11'lik bir artış olduğunu öne süren veriler sunmuştur. Sosyal jet-lag'in aynı zamanda daha kötü ruh hali, daha yüksek uyku hali ve yorgunluk ile ilişkili olduğu gerçeği hatırlatılmıştır (Geddes, 2019).

Sosyal jet-lag sendromu biyolojik ve sosyal zaman arasındaki düzensizliktir (hatalı hizalamadır) (Wittmann vd., 2006). Günlük yaşamda artan iş yükü ve iş stresi, vardiyalı çalışma, çevresel değişiklikler, yapay ışık kaynaklarına daha fazla maruz kalmanın yanı sıra aşırı tablet/akıllı telefon kullanımı, sosyal jet-lag sendromunun obezite, gündüz uyku hali ve yorgunluk, kötü ruh hali, depresyon ve metabolik ve kardiyovasküler bozukluklar gibi birçok sağlık sorunu ile ilişkili olduğu sonucunu getirmiştir. Sosyal jet-lag sendromunun azaltılması halk sağlığında önemli bir konudur (Zhang vd., 2019).

Sosyal jet-lag sendromunun bir nedeni, insanların normal biyolojik zamanlarından daha erken uyanmaları ve daha sonra hafta boyunca birikmiş uyku borcunu telafi etmek için serbest günlerde uyumaları, yani iş günlerinde yetersiz uyku uyumalarıdır (Wittmann vd., 2006: 497). $\mathrm{Bu}$ nedenle, uyku borcunu biriktirmeye karşı düzenli gündüz uykularının sosyal jet-lag sendromu semptomlarını hafifleteceğini varsaymak mantıklıdır (Roenneberg vd., 2012: 940).

Roenneberg'e göre sendrom, hafta sonu günlerinde daha geç uykuya geçildiğinde ve hafta içi günlerinde daha erken uykudan kalkıldığında meydana gelir. Normal jet-lag gibi sosyal olanı, vücudu iki zaman dilimi arasında değiştirmek zorunda kalmanın bir sonucudur; biri, iş ve sosyal yükümlülükler tarafından dikte edilir, diğeri iç zamanlama sistemimiz, sirkadiyen saattir. Araştırmalara göre çalışanların üçte ikisinin haftada en az bir saat sosyal jet-lag yaşadığ 1 ve iki saat ya da daha fazla deneyim yaşadığı tahmin edilmektedir. Ayrıca yaşanılan sosyal jet-lag, iki zaman dilimi arasındaki uyumsuzluğun büyüklüğüne de bağlıdır. İnsanların kronotipleri olarak bilinen uyku tercihi büyük ölçüde genlerden etkilenir (Geddes, 2019). Yine 2017 yılında Amerikan Uyku Tıbbı Akademisi'nde yapılan bir çalışma, düzensiz bir uyku programına sahip kişilerin, haftanın yedi günü düzenli bir uyku düzenini sürdüren insanlardan daha düşük ruh halleri, daha fazla sağlık sorunu ve daha fazla uyku işlev bozukluğu yaşadığını keşfetmiştir (Malbon, 2018). Bununla birlikte, sosyal jet-lag sadece uyku miktarını da bozmamaktadır. Lisans öğrencileri üzerinde yapılan bir araştırma, düzensiz uyku uyuyanların, daha tutarlı uyku programlarına sahip olanlardan çok daha düşük kaliteli uykuya sahip oldukları sonucuna ulaşmıştır. Düzensiz uyku da daha zayıf akademik performansla (başarıyla) ilişkilendirilmiştir. Melbourne'deki Monash Üniversitesi'nde çalışmayı yöneten Andrew Phillips'e göre bu durum, dikkatleri uyku konusunda düzenliliğin olması yönüne çekmiştir (Geddes, 2019).

Biyolojik açıdan ise yapılan bir diğer araştırma, daha yüksek sosyal jet-lag seviyesine sahip yetişkinlerin aşırı kilolu veya obez olma olasılığının (metabolik sendrom (tip 2 diyabet gelişimi ile ilişkili)), düzenli uyku düzenine sahip olanlara kıyasla daha yüksek olduğunu tespit etmiştir (Geddes, 2019). Son on yıldaki araştırmalar, hafta sonları uyku takvimini değiştirmenin; kalp, diyabet, depresyon ve bir dizi diğer kronik sağl1k problemlerine neden olduğu sonucunu da ortaya koymuştur (Burda, 2017; Clark, 2019). Ayrıca uyku yoksunluğu; uyanıklık, el-göz koordinasyonu, hafıza, mantıksal akıl yürütme gibi yönleriyle günlük hayatı da olumsuz etkilemektedir (Clark, 2019).

Tüm bu açıklamalar 1şığında, sosyal jet-lag için temel çözümün güzel ve uzun bir uykuya dalmak olacağını varsaymak yanlış olur. Sosyal jet lag, kırılması gereken negatif bir spiral yaratır ve uzmanlar, hafta sonları kayıp uykuyu yakalamayı planlayarak üstesinden gelemeyeceğinizi önermiştir. Bunun yerine, biraz daha erken uyumaya ve normalden biraz daha geç kalkmaya 
çalışmanın çok daha etkili olduğunu öne sürmüşlerdir. Böylece yaşam tarzı ile birlikte sirkadiyen ritim yavaş yavaş yeniden uyumlaştırılır. Bir diğer öneri ise, -kimine göre daha zor gelse de-, akı1lı telefonları, dizüstü bilgisayarları ve tabletleri yatak odasının dışında bırakmak ve yatmadan bir saat önce kullanmaktan kaçınmaktır (Clark, 2019).

Hünerli (2016)'ye göre ise sosyal jet-lag sendromu ile başa çıkma yolları şunlardır:

- En önemli adım, uyku düzeninin sağlanmasıdır. Kişinin uykusunun bir rutini olmalı ve mecbur kalınmadıkça hafta sonları da dahil olmak üzere bu rutinin dışına çıkılmamalıdır.

- Çalı̧̧ma saatleri içerisinde mutlaka günde en az 2-3 kez kısa aralar verilmeli, temiz hava alınmalı ve mümkünse çalışma ortamı havalandırılmalıdır.

- Gün 1şı̆̆ından olabildiğince yararlanılmaya çalışılmalıdır. Fırsat olduğunda öğle yemeğinde dışarıya çıkmalı, ofis ya da çalışma alanı 1şıktan maksimum düzeyde faydalanılacak şekilde düzenlenmeli, yemek ya da kahve molalarında pencereye yakın yerlerde bulunulmalı, gün ışı̆ı̆na yakın aydınlatmalar kullanılmalıdır.

- Beslenmeye dikkat etmeli ve bol miktarda sebze ve meyve tüketilmelidir. Özellikle öğle yemeklerinde karbonhidrat tüketimine dikkat edilmelidir.

- Alkol ve kafein kullanımına dikkat edilmeli, minimum düzeyde kullanılmalıdır.

- Aile-İş yaşamı dengesi için kişinin kendisine zaman yaratması gerekmektedir. Kişisel zamanda internet, televizyon, telefon gibi teknolojik aletlerden uzak durulmalıdır.

- Eğlenceli hafta sonu planları, gün içinde arkadaşlarla kısa kahve molaları gibi keyifli etkinliklerle sosyal yaşamı düzenlemek önem taşır.

-Yapmaktan keyif alınan, negatif enerjinin atılmasına yardımcı olan bir hobi mutlaka edinilmelidir.

Esasen, sosyal jet-lag sendromunu aşmak kişinin avuçları içerisindedir. Kişisel programına neyin uygun olduğunu ve mümkün olduğunca küçük değişiklikleri nasıl yapabileceğini bulması, kişinin yaşam tarzında farklılık yaratabilir.

\section{SOSYAL JET-LAG SENDROMUNUN DEĞERLENDİRILMESİ ÜZERİNE BİR ARAŞTIRMA}

\subsection{Araştırmanın Amacı ve Önemi}

$\mathrm{Bu}$ çalışma, sosyal jet-lag üzerine farkındalığı artırmak ve yüz yüze katılım ile özellikle bu sendroma maruz kalmış insanların yaşadığı sosyo-psikolojik etkileri ortaya çıkarmak amacını taşımaktadır. Kişilerin içinde bulunduğu sendromları belirtileri sonrasında adlandırmak, sorunlarla başa çıkmada ve sendromu yenmelerinde anahtar adımlardır ve büyük önem taşımaktadır. $\mathrm{Bu}$ sendromun bilinirliği ile de daha çok çalışan yaşam tarzını iyileştirme konusunda adımlar atacaktır. Söz konusu nihai hedeflerle bilimsel bir yayın ortaya çıkarılarak, yerli literatürümüze katkı sağlanmıştır.

\subsection{Araştırmanın Yöntemi}

Bu çalışmada nitel araştırma yöntemini esas alan, olgu bilim deseni kullanılmıştır. Farkında olduğumuz ancak derinlemesine ve ayrıntılı bir anlayışa sahip olmadığımız olgulara odaklanılması olgu bilim (fenemenoloji) deseni olarak adlandırılmaktadır. Nitel araştırmalar, gözlem, görüşme ve doküman inceleme gibi nitel veri toplama yöntemlerinin kullanıldı̆̆ algıların ve olayların doğal ortamında gerçekçi ve bütüncül bir biçimde ortaya konmasına yönelik sürecin izlendiği araştırmalardır. Nitel araştırmalarda elde edilen sonuçlar evrene genellenememekle birlikte, elde edilen sonuçlar, konuya ilişkin bir bakış açısı sağlaması bakımından önemlidir (Yıldırım ve Şimşek, 2018: 137). Ayrıca çalışma kapsamında yarıyapılandırılmış görüşme tekniği kullanılarak, katılımcıların kişisel duygu durumlarının bizzat gözlenmesi, anında sorulara geri dönüş alabilme, görüşmenin akışında değişikliğe gidilebilme serbestisi gibi özelliklerden yararlanılmıştır. 


\subsection{Araştırmanın Evreni ve Örneklemi}

Araştırma Konya'da bulunan Çumra Tarım Kredi Kooperatifi'nde görev yapan altı personelle gönüllü olarak gerçekleştirilmiştir. Bu personellerden ikisi kadın, diğerleri erkektir. Gizlilik esasına dayanarak araştırmaya katılan personelin gerçek isimleri kullanılmamıştır. Her birine bir kod ismi verilmiştir. Bunlar Seher, Gupset, Osman, Sami, Mustafa, Celaleddin'dir. Araştırmaya katılan personelin mesleki deneyimleri ortalama on yıldır. Yapılan görüşmeler sonucunda personelin aktif iş yaşamında bulunmaları sebebiyle sosyal jet-lag sendromuna maruz kaldıkları belirlenmiştir. Tablo 1'de katılımcıların demografik bilgilerine yönelik özet bilgiler yer almaktadır.

Tablo 1. Çalışma Grubundaki Katılımcılara İlişkin Demografik Bilgiler

\begin{tabular}{|l|l|l|}
\hline Katılımcı Adı & Görevi & Ĕgitim Durumu \\
\hline Seher & Yetkili Memur & Lisans \\
\hline Gupset & Müdür Yardımcısı & Lisans \\
\hline Osman & Müdür & Lisans \\
\hline Sami & Memur & Önlisans \\
\hline Mustafa & Memur & Önlisans \\
\hline Celaleddin & Hizmetli & Lise \\
\hline
\end{tabular}

\subsection{Araştırmada Tercih Edilen Veri Toplama Süreci}

Yazarlar, yarı yapılandırılmış görüşme tekniğinin gerektirdiği şekilde araştırmanın genel amacı ve sorularına yönelik görüşme soruları hazırlamıştır. Görüşmede hazırlanan soruların bir grup birey ile denenmesi ve bu denemeye göre gerekli ifade değişikliklerinin yapılması ve gerekirse yeni sorular yazılması önemlidir (Yıldırım ve Şimşek, 2008: ). Bu nedenle, araştırmacılar, personellerden biriyle ön görüşme gerçekleştirmiştir. Daha sonra bu görüşme incelenmiş ve gerekli değişikler sorular üzerinde yapılmıştır.

Araştırmaya katılan personellerin her birinin isteği üzerine öğle saatlerinde görüşmeler gerçekleştirilmiştir. Yapılan görüşmelerde, küçük boy etiket, not defteri ve kalem kullanılmıştır. Görüşmeler her bir personel için belirlenen sayfalara not alınmış ve sırayla numaralandırılmıştır. Verilen cevapların gizli tutulması esası personele hatırlatılarak görüşmeler sonlandırılmıştır. Yapılan görüşmeler en az 30, en fazla 50 dakika sürmüştür. Buna göre araştırmada toplam 240 dakika süreli, 21 sayfa veri elde edilmiştir. Araştırmanın görüşme soruları (Ek) şunlardır:

1. Kendinizi kısaca tanıtır misınız?

2. Uyku düzeniniz nasıldır? Gün içerisinde uyku problemleri yaşıyor musunuz?

3. Sosyal Jet-Lag Sendromu hakkında bilginiz var mı? Bu konu hakkında ne düşünüyorsunuz?

4. Sosyal Jet-Lag Sendromunun günlük aktivitelerinizde ne gibi sonuçlar doğurduğunu düşünüyorsunuz?

5. Sosyal Jet-Lag Sendromunu yaşamamanız adına geliştirdiğiniz yöntemler var mıdır? Varsa bunlar nelerdir?

\subsection{Verilerin Analizi}

Nitel araştırma yaklaşımı doğrultusunda tasarlanan bu araştırmada "içerik analizi" yapılmıştır. Verilerin içerik analiziyle incelenmesinin nedenleri olarak şu ifadelere yer verilebilir (Yıldırım ve Şimşek, 2008: 178);

- Temel amacının toplanan verileri açıklayabilecek kavramlara ve ilişkilere ulaşmak olması, 
- İçeriklerle ilgili ortak ve sistematik verilere ulaşmayı öngörmesi,

- Mevcut metinlerin nitel ve nicel boyutlarından hareketle bilinmeyen sosyal gerçeğe yönelik çıkarım yapmak istemesi,

- Esas olarak birbirine benzeyen verileri belirli kavramlar ve temalar çerçevesinde bir araya getirerek bunları okuyucunun anlayabileceği bir biçimde düzenleyecek yorumlamaya firsat vermesi,

- Verileri daha derin bir işleme tabi tutması gibi özelliklerinden kaynaklanmaktadır.

\subsection{Araştırmanın Bulguları}

$\mathrm{Bu}$ bölümde görüşme yapılan personelin verdikleri bilgilerden elde edilen bulgular yer almaktadır. Ancak, yapılan analiz sonucunda ulaşılan verilerin zenginliği nedeniyle, araştırma bulgularının tamamına bu makalede yer verilmemiştir. Çalışmada bulgular aktarılırken yaygın görüşü belirtmek amaciyla frekansı en yüksek olan tema ve alt temalara ilişkin örnekler verilmiştir. Araştırmanın bulgularını oluşturan 4 tema şu şekilde sıralanabilir: 1. Uyku düzeni ve uyku problemleri, 2. Sosyal Jet-lag Sendromu hakkında düşünceler, 3. Sosyal Jet-lag Sendromunun Sonuçları, 4. Sosyal Jet-lag Sendromunu önleme tedbirleri.

\subsubsection{Uyku düzeni ve uyku problemleri}

Personellerin uyku düzeni ile ilgili olarak; Gupset ve Seher'in kadın olmaları sebebiyle işten sonra eve gittiklerinde çocukları ile alakadar olmaları gerektiğinden ve evin birçok sorumluluğunun kendi üzerlerinde olması sebebiyle belirli bir uyku düzenlerinin olmadığını ve bunun sonucunda da gün içerisinde uykusuzluk yaşadıklarını belirtmişlerdir. Hafta içi günlerinde iş çıkışı eve gidiş saatleri geç olmasından dolayı birçok işi hafta sonu günlerine bıraktıkları ve hafta sonunda da hafta içi yaşadıkları yorgunluğu atma firsatı bulamadıklarını belirtmişlerdir. Erkek personellerimizden ise Osman, Sami, Celaleddin ve Mustafa'nın belirli bir uyku düzenlerinin olduğu ancak yine de iş sabahları erken uyanmak zorunda olmalarından kaynaklı olarak gün içerisinde uykusuzluk sorunu yaşadıklarını belirtmiş̧lerdir. Uyku ihtiyaçlarını hafta sonu izin günlerinde karşılamak adına geç saatlerde uyandıkları, bunun sonucunda da özellikle pazartesi günü yani ilk iş gününde uyku sorunu ile daha çok karşılaştıklarını belirtmişlerdir.

\subsubsection{Sosyal Jet-lag Sendromu Hakkında Düşünceler}

Personelin hepsi jet-lag sendromu hakkında sahip oldukları görüşleri çeşitli şekillerde ifade etmiş̧lerdir. Hepsinin ortak tanımı "uzun süren uçak yolculukları sonrasında ortaya çıkan biyolojik saat ile iniş yapılan yerin saatinin uyuşmamasından kaynaklı bir rahatsızlık" olduğunu söylemişlerdir. Sosyal Jet-lag Sendromu denildiğinde ise personellerden Osman "Sosyal hayatımızda karşılaştığımız zaman problemleri, gün içerisinde yaşanan uyku sorunları bu sendromu tanımlayabilir." demiştir. Diğer personellerin verdikleri cevaplardan çıkarılan yorum şudur; kavramın aslında bilindiği hatta hepsinin bu sendromu yaşadığını fark ettiği fakat tam olarak tanımlayamadıkları görüşmeler sonucunda anlaşıllmıştır.

\subsubsection{Sosyal Jet-lag Sendromunun Sonuçları}

Görüşülen personelden Sosyal Jet-lag Sendromunu tanımlamaları istenmesinin ardından kendilerine Sosyal Jet-lag Sendromunun açıklaması yapılmıştır. Açıklama yapıldıktan sonra tüm personelin bu sendromu yaşadığını belirttiği ve hatta personellerden Seher, "Bahsettiğiniz tanimlamay biliyorum aslında bir önceki soruda da bunu ifade etmek istedim ama tam anlamıla kelimelere dökemedim ve gün içerisinde bu sendromu bir çok kez yaşadığımı söyleyebilirim." demiştir. Diğer bir personel Mustafa ise "Gün içerisinde uykusuzluk yaşadığım zamanlarda işlerime konsantrasyon olmakta zorlanıyorum, bu durum sonucunda da işime karşı isteksiz tavırlar sergilediğimi görüyorum. Çalı̧̧ma arkadaşlarıma karşı anlayışsız ve tahammülsüz davrandığımın da farkındayım. İs bitişi eve döndüğ̈̈mde ailem ise yorgunluğumu gözlemlediklerini ve hatta işimden dolayı mutsuz olduğumu düşündüklerini birçok kez 
belirttiler." Personellerin sıraladığı sonuçlar ise şu şekilde sınıflandırılmıştır; uykusuzluk, isteksizlik, sürekli yorgunluk, dikkat ve konsantrasyon bozukluğu, stres, gerginlik, öfke, tahammülsüzlük, umutsuzluk, mutsuzluktur.

\subsubsection{Sosyal Jetlag Önleme Tedbirleri}

Personellerin hepsinin bu sendromu yaşadığını ve gün içerisinde bu sendrom sebebiyle karşılaştıkları sorunlarla baş edebilmek ve bu yaşadıkları sendromu önlemek adına hemen hemen hepsinin kendince bazı önerileri olmuştur. Bunlar; Sami, “... gün içerisinde yaşadığım uykusuzluk sorununu çözmek adına iş yerimin evime yakın olmasindan faydalanarak öğle yemeği arasında eve gittiğimde ksa bir uyku molası verip günün geri kalan saatlerinde daha dinç kalmayı sağllyorum." demiştir. Gupset, "Çocuklarımla geçirdiğim her zaman dilimi benim için çok klymetli ve onlarla vakit geçirdiğim zaman gün içerisinde işimle ilgili ya da eve geldiğimde beni bekleyen diğer sorumluluklarımın yaşattı̆̆ yorgunluğu onlarla vakit geçirerek atıyorum ve hayata karşı pozitif enerji ile dolu oluyorum." demiştir. Celalettin ise "İ̧sten çıktıktan sonra bazı günler hemen eve gitmeyip arkadaşlarımla vakit geçirip, onlarla izin günleri için planlar yapıyoruz. İzinli olduğumuz günlerde alarm kurmadan uyanıp uykumuzu aldıktan sonra güzel Pazar kahvaltı planlarımızı gerçekleştiriyoruz ki bu da tüm hafta yorgunluğumu atıp kendimi iyi hissetmemi sağllyor." demiştir.

\section{TARTIŞMA VE SONUÇ}

Sosyal jet-lag'ın varlığı, çoğu insanın uyumsuz bir vücut saatine sahip olduğunu, sağlığı ve refahı olumsuz etkilediği bilinen bir soruna sahip olduğunu göstermiştir. Daha açık bir ifadeyle, uykuya yönelik bakış açısının yanlışlığı beraberinde olumsuz sonuçları doğurmuştur. Esasen yıllardır uzmanlar, herkes için önemli görülen standart bir uyku saati önermişlerdir. Sosyal jet-lag ise belki de yanılmış olunduğunu ve sağlık ve yaşam tarzı sonuçları açısından uyku ritminin taşıdığı önemi çarpıcı sonuçlarla ortaya koymuştur (Clark, 2019).

Bu çalışmada, yapılan araştırma sonrası elde edilen bulgulardan ortaya çıkan en önemli tartışma konularından biri Sosyal Jet-Lag Sendromunun insanlar tarafindan henüz yeteri kadar (bilinçli bir şekilde) bilinen bir kavram olmadığı, bu konuda bilgilenmenin eksik olduğu sorunudur. Üçte ikimizin haftada en az bir saat sosyal jetlag yaşadığı ve iki saat ya da daha fazla deneyim yaşadığ 1 tahmin edilmektedir. Bunun sonucunda yaşanılan bu sağlık sorunu konusunda kişilerin daha bilinçli hale getirilmesinin gerekliliği ortaya konulmuştur.

Başka bir tartışma konusu ise yaşanılan bu sendrom ile nasıl başa çıkılması gerektiği noktasında kişilerin bu konuda eksik bilgilere sahip olması ve tam olarak ne yapmaları gerektiğini bilmemeleri sorunsalıdır. Sosyal Jetlag Sendromu ile başa çıkma yollarının kişilerin ulaşabileceği kaynaklarda paylaşılması, kavramın bu konudaki eksikliğinin giderilmesi gerekliliğine dikkat çekilmesi gerekmektedir.

Kavramın henüz yeni ortaya çıkan bir kavram olması sebebiyle sosyal jetlag sendromunun sonuçlarının tam anlamıyla sınıflandırılmasında da eksiklik olduğu yapılan görüşmeler sonucunda ortaya koyulmuştur.

Konu üzerine ileride yapılacak çalışmalara getirilen öneriler ise şunlardır:

1. Araştırmadan elde edilen verilerin genellenebilmesi amacıyla, araştırma farklı çalışma ortamlarında, farklı katılımcılarla ve farklı araştırmacılarla yinelenebilir.

2. Farklı araştırma yöntemleri kullanılarak Sosyal Jetlag Sendromu'nu değerlendirmeye yönelik araştırmalar desenlenebilir.

3. Kamu ve özel sektörde çalışan kişilerle de görüşmeler gerçekleştirilerek elde edilen bulgular, bu araştırmanın bulgularıyla karşılaştırılabilir. 


\section{KAYNAKÇA}

Burda, Doğan (2017). Dikkat! Sosyal jet lag kalbinize kötü geliyor. Erişim Adresi: https://www.hurriyet.com.tr/kelebek/saglik/dikkat-sosyal-jet-lag-kalbinize-kotu-geliyor40556545 (Erişim Tarihi: 17.01.2020).

Clark, Neil (2019). Social Jetlag. Erişim Adresi: https://www.sleepcycle.com/sleepdeprivation/social-jetlag/ (Erişim Tarihi: 21.01.2020).

Geddes, Linda (2019). Social jetlag - are late nights and chaotic sleep patterns making you ill? Erişim Adresi: https://www.theguardian.com/lifeandstyle/2019/jan/21/social-jetlag-are-latenights-and-chaotic-sleep-patterns-making-you-ill (Erişim Tarihi: 17.01.2020).

Hünerli, Gizem (2016). Sosyal Jet-Lag Sendromu. Erişim Adresi: https://www.tavsiyeediyorum.com/makale_17038.htm (Erişim Tarihi: 19.12.2019).

Malbon, Abigail (2018). Social jet lag could be the reason why you're so tired all the time. Erişim Adresi: https://www.cosmopolitan.com/uk/body/health/a22715169/what-is-social-jet-lag/ (Erişim Tarihi: 20.01.2020).

Roenneberg, Till (2012). Internal Time: Chronotypes, Social Jet Lag, and Why You're So Tired. Harvard University Press.

Roenneberg, Till, Allebrandt, Karla V., Merrow, Martha ve Vetter, Celine (2012). Social jetlag and obesity. Curr Biol., 22(10): 939-943.

Wittmann, Marc, Dinich, Jenny, Merrow, Martha ve Roenneberg, Till (2006). Social jetlag: misalignment of biological and social time. Chronobiol Int., 23(1-2): 497-509.

Yıldırım, Ali ve Şimşek, Hasan (2008). Sosyal Bilimlerde Nitel Araştırma Yöntemleri. Ankara: Seçkin Yayıncilık.

Zhang, Zhongxing, Cajochen, Christian ve Khatami, Ramin (2019). Social Jetlag and Chronotypes in the Chinese Population: Analysis of Data Recorded by Wearable Devices. J Med Internet Res., 21(6): e13482 (Erişim Adresi: https://www.ncbi.nlm.nih.gov/pmc/articles/PMC6595939/, Erişim Tarihi: 23.03.2020).

EK

\section{GÖRÜŞME FORMU}

Araştırma Sorusu: Sosyal Jet-Lag Sendromu Nedir?

Yer:

Tarih ve Saat:

Giriş:

Merhabalar. Yapılacak olan bu görüşmede temel amaç; ülkemizde Sosyal Jet-Lag Sendromunun kişiler üzerinde ne ifade ettiğini betimlemek ve bu durumun olumlu ve olumsuz yanlarını ortaya çıkartarak alan yazına katkı sağlamaktır. Bu araştırma sonuçlarının kişiler üzerinde yaşanılan problemlerin çözümünde öneriler sunulmasına katkıda bulunacağı düşünülmektedir.

Sizlerle görüşmelerden elde edilecek bilgiler gizlidir ve kimliğiniz ifşa edilmeyecektir. Soruları cevaplarken rahat olmanız ve gerçekleri yansıtmanız beklenmektedir. Katılımınız için teşekkür ederiz. 


\section{Görüșme Soruları:}

1. Kendinizi kısaca tanıtır misınız?

2. Uyku düzeniniz nasıldır? Gün içerisinde uyku problemleri yaşıyor musunuz?

3. Sosyal Jet-Lag Sendromu hakkında bilginiz var mı? Bu konu hakkında ne düşünüyorsunuz?

4. Sosyal Jet-Lag Sendromunun günlük aktivitelerinizde ne gibi sonuçlar doğurduğunu düşünüyorsunuz?

5. Sosyal Jet-Lag Sendromunu yaşamamanız adına geliştirdiğiniz yöntemler var mıdır? Varsa bunlar nelerdir? 